\title{
Truck Cab Design: Perceptions of Women Truck Drivers
}

\author{
Jeanette Black ${ }^{1}$, Ellen Voie ${ }^{2}$, Matt Maurer ${ }^{1}$, Jane Palakeel ${ }^{1}$ and William Chacon ${ }^{1}$ \\ 1. Department of Operations and Management, College of STEMM, University of Wisconsin Stout, Menomonie Wisconsin \\ 54751-0790, USA
}

2. Women in Trucking, Inc., Plover, Wisconsin 54467-0400, USA

\begin{abstract}
The trucking industry is a major force behind the United States (US) economy with approximately 750,000 interstate motor carriers. Trucks deliver $70 \%$ of all freight tonnage while $80 \%$ of U.S. communities receive goods exclusively by truck. The motor carrier industry provides jobs, generating significant income and tax revenue, representing approximately 5\% of U.S. GDP (gross domestic product). Despite one of every 13 people employed in a trucking-related job, there is a significant driver shortage. The ATA (American Trucking Associations) currently projects a shortage of 20,000 to 25,000 drivers in the for-hire truckload market. Women are well positioned to address this shortage. In 2011, women represented $7 \%$ of total employment in the U.S. trucking industry. The purpose of this study was to identify truck design needs for women truck drivers. This research is significant due to limited data sources about truck design needs for women drivers. This study also contributes to the body of knowledge about women in the trucking industry. In response, a 33-question survey was developed using Qualtrics ${ }^{\mathrm{TM}}$ survey software. In April, 2012, an electronic survey was distributed to 663 Women in Trucking Association members over a two-week period with a response rate of $18 \%$. Results were separated into quantitative and qualitative data and analyzed accordingly. Adjustability was a central issue facing women truck drivers. Recommendations for seat design, side mirrors, steps, handrails, hydraulic hood lifters, and steering consoles will be presented. Limitations of the study and recommendations for future research will be discussed.
\end{abstract}

Key words: Truck cab design, women truck drivers, trucking industry, needs assessment.

\section{Introduction}

The trucking industry is a major force behind the United States (US) economy with approximately 750,000 interstate motor carriers. Trucks deliver $70 \%$ of all freight tonnage while $80 \%$ of U.S. communities receive goods exclusively by truck. The motor carrier industry provides jobs, generating significant income and tax revenue, collecting more than $\$ 650$ billion in revenue. This represents approximately $5 \%$ of U.S. GDP (gross domestic product). Despite one of every 13 people employed in a trucking-related job, there continues to be a significant driver shortage.

A 2012 report by ATA (American Trucking Associations) currently projects a shortage of 20,000 to 25,000 of drivers in the for-hire truckload market in the U.S.A. [1, 2]. Deregulation of the motor carrier industry dating from the 1980 s has been credited for

Corresponding author: Jeanette Black, Dr., E-mail: blackj@uwstout.edu. increased growth of the industry and a demand for drivers [3]. According to the published literature, at least one fifth of all long-haul drivers are age 55 and older and it is expected that a larger percentage of long haul heavy duty truck drivers in the transportation industry will be older with within the next decade resulting in an increase in retirements [4, 5].

The beneficial aspects of being a truck driver involve several aspects: independence, ability to make decisions, operation of new and better trucks, high income potential, and ability to explore and travel to different parts of the country [6]. In terms of income potential for women truck drivers, the average starting median income can be upwards of $\$ 30,000$ annually USD (E. Voie, personal communication, February, 25, 2014). However, a review of the literature reveals wide variability regarding annual median incomes reported in the United States for women drivers as well as their male counterparts. A study by Stephenson and Fox [7] reported the average median income of drivers was 
approximately $\$ 40,000$ per year USD, while a study by Valway, Jenison, Keller, Vega-Hernandez, and McCree published regarding truck drivers $(N=652)$ in New Mexico that the annual median income for women drivers was approximately $\$ 50,000$ per year USD versus $\$ 61,000$ per year USD for male drivers. The Bureau of Labor Statistics in 2012 reported the annual median income of women drivers was approximately $\$ 27,924$ per year USD with the annual median income of male drivers reported at approximately $\$ 38,272$ per year USD [8]. Factors that may influence the reporting of annual median income data in the literature may be related to the hours or service regulation rules, anti-discrimination laws in the United States, and low reporting (V. Walker, personal communication, February 25, 2014).

Although these are attractions to the industry, truck drivers spend long hours behind the wheel, working an average of 41.5 hours per week [9]. Long hours, driver shortages, and challenging working conditions are related to the high turnover rates in the trucking industry compared with the overall labor force considered in its entirety [3, 7]. Truck drivers are subject to HOS (hours of service regulations) by the DOT (Department of Transportation). These rules limit drivers to 60 hours of work time in 7 days and require an 8-hour break after 10 hours of driving and 15 hours of total work time [10]. Such limitations impact the median income of drivers and may be a contributing factor regarding the wide range of variability in reported annual median income data among the truck driver population in the United States.

Although the research recommends the industry focus on scheduling greater home time, increasing pay, improved benefit packages, technology assistance for government paperwork requirements, driver skill, safety, and decreasing driver stress, there has been limited focus on the truck cab design needs for the trucking industry specifically focused on women [6]. A well-designed truck cab not only makes a significant difference in the working conditions for a truck driver but also affects the safety of truck drivers and other road users. If the design of the truck cab is poorly fitted to the size and dimensions of the driver, the road may be less visible, driving controls may be more difficult to reach, and seat belts may be less comfortable and less likely to be used-all of which increase the risk of injury to the driver and other road users.

In 2011, women represented $7 \%$ of total employment in the U.S. trucking industry [8]. This new demographic reality necessitates an updating of the data used for the design of truck cabs because of the link to various demographic characteristics [11, 12]. Given the previous discussion regarding the continued driver shortage, there is a pressing need to enhance ergonomic cab designs for safe and efficient over-the-road operation, especially for women drivers. A 2012 study by Jinhua, Hongwei, Bradtmiller et al. [13], found that although male truck drivers were shorter in stature, female truck drivers were not different from the U.S. general population. Demographic evidence suggests that the population is changing, with a greater representation of racial and ethnic minorities, especially the Hispanic ethnic group. In 1983, the combined category of truck drivers (heavy and light) and driver-sales workers included $11.7 \%$ African Americans, 5.6\% Hispanics, and 3.5\% females [14]. In 2009, the category of driver-sales workers and truck drivers included 13.4\% African Americans, 18.7\% Hispanics, and 5.2\% females [15]. Improvements in the quality of the driver working environment, comfort, and driver experience are recommended to attract, retain, and enhance profitability for the industry [7, 16-19]. This study focuses on eliciting the perceptions of women truck drivers regarding the design and equipment needs and recommendations for Class 8 trucks. This study seeks to inform and add to this body of literature.

\section{Methods}

The study sample consisted of 663 female truck drivers who were members of the WIT (Women in 
Trucking) Organization, located in Plover, Wisconsin, U.S.A. Survey questions were designed based on available information from the literature, interviews with Ellen Voie, President for Women in Trucking, and an experiential assessment exercise evaluating a new 2012 Class 8 Model Truck and a used Class 8 Model Truck at a local dealership in March 2012. The survey was a component of an applied learning project for a graduate level course and was developed as an online survey using Qualtrics ${ }^{\mathrm{TM}}$ survey software. Data were collected across the continental United States. The survey used convenience sampling methods and was distributed to WIT members for a two-week period in April 2012. Only those participants with a valid Class A Commercial Vehicle Driver's License (CDL) were included for analysis in this study [20].

\section{Results}

A survey was developed using a 4 point Likert scale rating with an open-ended question text boxes following each question option. Survey question design resulted from an experiential learning exercise with students in March 2012 using 1 new Class 8 truck and 1 used Class 8 truck as exhibits. Survey questions were formulated, edited, and reviewed by the President of WIT, course professor, and the students. The population sample was a convenience sample of the membership from the WIT organization in a 2-week time frame in April 2012. The electronic survey was developed in Qualtrics and e-mailed to 633 WIT members with a resulting response rate of 122 or $18 \%$. Questions 1 through 6 of this survey provide the demographics of the sample representing the quantitative portion of this study. The remaining questions and results of the survey are qualitative in nature and reported in terms of frequency with central themes and subthemes derived from the qualitative analysis with recommendations for truck cab improvement [21]. Limitations for future survey design and distribution will be discussed in the recommendations section.

\subsection{Quantitative results}

Tables 1-6 represented the quantitative results for this study. Of this sample, $88 \%$ or survey participants represented driving Class 8 (heavy duty) trucks with $10 \%$ driving medium duty trucks. Participants indicated that they had been driving for 5 years or longer. Thirty-three percent of participants reported driving 4 hours per day while $49 \%$ indicated driving 5 hours per day or more. Seventy-five percent of respondents

Table 1 What type of truck do you usually drive?

\begin{tabular}{llllll}
\hline$\#$ & Answer & Response & Frequency (\%) & Statistic & Value \\
\hline 1 & Heavy duty (Class 8) & 101 & $89 \%$ & Min. value & 1 \\
2 & Medium duty & 10 & $9 \%$ & Max. value & 3 \\
3 & Light duty & 2 & $2 \%$ & Mean & 1.12 \\
& & & Variance & 0.15 \\
& & & Standard deviation & 0.38 \\
\hline
\end{tabular}

Table 2 How long have you been driving this truck?

\begin{tabular}{llllll}
\hline$\#$ & Answer & Response & Frequency (\%) & Statistic & Value \\
\hline 1 & Less than 6 months & 8 & $7 \%$ & Min. value & 1 \\
2 & 6 months to less than 1 year & 7 & $6 \%$ & Max. value & 5 \\
3 & 1 year to less than 3 years & 18 & $16 \%$ & Mean & 4.04 \\
4 & 3 years to less than 5 years & 20 & $18 \%$ & Variance & 1.59 \\
5 & 5 years or more & 60 & $53 \%$ & Standard deviation & 1.26 \\
& & & & \\
\hline
\end{tabular}


Table 3 How many hours/day do you spend driving this truck?

\begin{tabular}{llllll}
\hline$\#$ & Answer & Response & Frequency (\%) & Statistic & Value \\
\hline 1 & 1 hour/day & 5 & $4 \%$ & Min. value & 1 \\
2 & 2 hours/day & 2 & $2 \%$ & Max. value & 5 \\
3 & 3 hours/day & 14 & $12 \%$ & Mean & 4.19 \\
4 & 4 hours/day & 37 & $33 \%$ & Variance & 1.05 \\
5 & 5 hours/day or more & 55 & $49 \%$ & Standard deviation & 1.03 \\
\hline & & & & & \\
\hline
\end{tabular}

Table 4 The cab of this truck is comfortable for your body type.

\begin{tabular}{llllll}
\hline$\#$ & Answer & Response & Frequency (\%) & Statistic & Value \\
\hline 1 & Yes & 85 & $76 \%$ & Min. value & 1 \\
2 & No & 27 & $24 \%$ & Max. value & 2 \\
& & & & Mean & 1.24 \\
& & & & Variance & 0.18 \\
& & & & Standard deviation & 0.43 \\
\hline
\end{tabular}

Table 5 Do you feel safe when driving the truck?

\begin{tabular}{llllll}
\hline$\#$ & Answer & Response & Frequency (\%) & Statistic & Value \\
\hline 1 & Yes & 105 & $92 \%$ & Min. value & 1 \\
2 & No & 9 & $8 \%$ & Max. value & 2 \\
& & 114 & & Mean & 1.08 \\
& & & & Variance & 0.07 \\
& & & Standard deviation & 0.27 \\
\hline
\end{tabular}

Table 6 Are you satisfied with how your truck handles while driving?

\begin{tabular}{llllll}
\hline$\#$ & Answer & Response & Frequency (\%) & Statistic & Value \\
\hline 1 & Yes & 100 & $90 \%$ & Min. value & 1 \\
2 & No & 11 & $10 \%$ & Max. value & 2 \\
& & & Mean & 1.1 \\
& & & Variance & 0.09 \\
& & & & Standard deviation & 0.3 \\
\hline
\end{tabular}

reported they were satisfied with their current truck and $92 \%$ of participants replied feeling safe while driving their truck on the highways, interstates, and byways.

\subsection{Qualitative Results}

The remaining survey questions focused on the qualitative items of the survey by eliciting feedback about the issues that women face in terms of truck cab design of Class 8 trucks. The questions were designed as open ended with a response section for recommendations for improvement in these areas.
Central themes and subthemes were analyzed using qualitative coding methods to explicate frequency of these themes and subthemes [21].

The qualitative analysis for Table 7 identified the central theme of safety. Eight percent of respondents reported that safety was a concern when driving the truck. The subthemes identified were lack of truck seats designed for women both from an anthropometric and ergonomic design standpoint resulting in uncomfortable and lack of adjustability of the seat mechanism to meet the needs of women truck drivers. 
In addition, survey respondents also indicated that the lack of airbags in the Class 8 trucks they drove did not include airbags (20\%). The subtheme of airbags was aligned with the central theme of safety.

Table 8 inquired about satisfaction of truck handling of the Class 8 trucks driven by survey respondents. The analysis revealed that survey respondents were equally divided in terms of dissatisfaction. Feedback of respondents identified issues in the areas of suspension and truck handling as opportunities for improvement related to overall truck design.

Table 9 is attempted to explore satisfaction in more detail as to results in Table 7. Regarding the central theme of suspension, adjustable lumbar support (81\%) was perceived by respondents as a primary need for improvement. This was followed by seat comfort (61\%) and adjustability of seat belts (45\%), respectively. Study participants who responded to this question recommended greater adjustability and comfort in the design of these features for Class 8 trucks.
Analysis of the results in Table 10 is focused on the design and position of the steering wheel of the Class 8 truck. Analysis this question identified three central themes in the areas of: position, dimensions, and rotation concerning the steering wheel mechanism. Regarding steering wheel position, $58 \%$ of survey respondents identified the steering wheel design as uncomfortable and/or obstruction for viewing the truck dashboard. Fifty-two percent of respondents reported that the steering wheel design was too small with a recommendation of design sized with the driver. Rotation of the steering wheel was the third most common theme $(47 \%)$. Respondents reported that the steering wheel mechanism was difficult to turn while driving.

Table 11 is focused on the adjustability of the foot pedals for Class 8 truck. Adjustability of foot pedals was a central theme and concern of study participants (77\%). Subthemes identified were: adjustability, materials used for foot pedal design, position, and overall

Table 7 What could be improved in terms of safety of the truck?

\begin{tabular}{llll}
\hline Central theme & Frequency (\%) & Subtheme & Recommendation \\
\hline Seat belt adjustability & $80 \%$ & $\begin{array}{l}\text { Seat restraint systems built for women } \\
\text { Uncomfortable seats } \\
\text { Less flexibility in seat position }\end{array}$ & $\begin{array}{l}\text { Make seat belt adjustable } \\
\text { Change the seat design }\end{array}$ \\
\hline Airbags & $20 \%$ & Airbags not available & Addition of airbags \\
\hline
\end{tabular}

Table 8 Are you satisfied with how your truck handles while driving?

\begin{tabular}{llll}
\hline Central theme & Frequency $(\%)$ & Subtheme & Recommendation \\
\hline Not satisfied & $9 \%$ & Suspension & Air ride \\
Not satisfied & $9 \%$ & Handling & More wind resistance \\
\hline
\end{tabular}

Table 9 Which of the following components of your truck seat are you not satisfied with in terms of design?

\begin{tabular}{llll}
\hline Central theme & Frequency $(\%)$ & Subtheme & Recommendation \\
\hline Adjustable lumbar support & $81 \%$ & Adjustability & Better position for women \\
\hline Seat comfort & $61 \%$ & Cushioning & $\begin{array}{l}\text { Softer seat } \\
\text { Better absorption } \\
\text { Softer ride }\end{array}$ \\
\hline Seat belt & $45 \%$ & $\begin{array}{l}\text { Adjustability } \\
\text { Positioning }\end{array}$ & $\begin{array}{l}\text { Upright position of seatbelt } \\
\text { Reduce neck irritation due to placement }\end{array}$ \\
\hline
\end{tabular}

Table 10 Which of the following components of your truck steering wheel are you satisfied with in terms of design?

\begin{tabular}{llll}
\hline Central theme & Frequency $(\%)$ & Subtheme & Recommendation \\
\hline Positioning & $58 \%$ & Obstructed view of dashboard & Tilt steering \\
& $52 \%$ & Uncomfortable & Height adjustability \\
\hline Dimensions & Too Small & Steering wheel sized to the driver \\
Rotation & $47 \%$ & Difficult to turn & Power steering standard for all trucks \\
\hline
\end{tabular}


Table 11 Which of the following components of your truck pedals are you not satisfied with in terms of design?

\begin{tabular}{llll}
\hline Central theme & Frequency $(\%)$ & Subtheme & Recommendation \\
\hline & & Material & Non-slip material (design) \\
Adjustable Pedals & \multirow{2}{*}{$77 \%$} & Design & Wider pedals \\
& & Adjustability & Adjustment for short and long legged people \\
& & Positioning & Placement of clutch \\
& & Wider pedal area \\
\hline
\end{tabular}

design of the pedal were problematic for women drivers. Study participants recommended opportunities for improvement in areas of: non-slip materials, wider design, pedal adjustability, and overall design regarding clutch placement.

Table 12 is focused on the perceptions of women drivers in terms of the cabin facilities of Class 8 trucks. Survey respondents identified the following central themes related to satisfaction levels: mattress and cabin space (60\%), bunk design (42\%), and storage facilities (36\%). Survey respondents recommended opportunities for improvement in the areas of: mattress quality, increased and adjustable storage space, versatility, comfort, and other amenities.

Table 13 is focused on the perception of women truck drivers in terms of Class 8 transmission design. Central themes identified were: ease of use (86\%), location (42\%), and clutch (35\%). Analysis of qualitative responses yielded the following subthemes: exactness of shifting capability, location of gear shifter, and the reachability of the clutch. Opportunities for design improvements that were associated with these themes and subthemes were: easier and smoother shifting and gear transition, options for ordering automatic transmissions and/or having manufacturers make automatic transmissions standard design features, and adjustability of the gear shifter. Survey participants recommended better locations for clutch placement and adjustability to better meet the design needs of women truck drivers.

Table 14 is focused on the perception of women truck drivers related to truck instrument console design. Central themes identified were related to: dashboard (69\%), lighting (59\%), and cabinets (39\%). Reachability was the primary subtheme for respondents for dashboard and cabinetry. Survey respondents recommended opportunities for improvement for instrument console design in the areas of dash design, improved lighting options, and the availability and reachability of cabinet doors that open and close, rather than the industry standard of stretchable mesh materials.

Table 15 is focused on women truck drivers regarding perceptions about accessibility to the Class 8 engine compartment. Central themes identified were related to: access to the fuel tank (74\%), ability of lifting the truck hood (50\%), and ease in closing the truck hood $(43 \%)$. Subthemes identified were: the jumping of the pump handle when fueling which precipitated the potential for fuel spills, heavy weight of the truck hoods, difficulty in closing truck hood latches, and reduced visibility. Analysis of recommendations for improvement related to truck design were: develop a more ergonomic dash design, additional lighting to improve visibility, and materials to address the weight and difficulty in the opening and closing of the truck hood.

Table 16 depicted the feedback from survey respondents regarding side mirrors. Size mirror size and adjustability were the central themes identified. Survey respondents reported that size mirrors were too small, narrow, and/or lacked adjustability. Opportunities for improvement included designing longer and wider mirrors including the ability of electrical adjustment, similar to standard passenger vehicles.

Table 17 explicated the perceptions of survey respondents regarding accessibility to the truck cab. Step spacing (37\%) and step width (48\%) revealed challenges women truck drivers face on a consistent basis. Subthemes identified spacing between steps in general and for entrance into the truck cab were too 
Table 12 Which of the following components of your truck's cabin facilities are you not satisfied with in terms of design?

\begin{tabular}{llll}
\hline Central theme & Frequency (\%) & Subtheme & Recommendation \\
\hline Mattress and cabin space & $60 \%$ & Better mattresses & $\begin{array}{l}\text { Higher quality mattresses, } \\
\text { Bigger and comfortable }\end{array}$ \\
\hline & & & $\begin{array}{l}\text { Bunk versatility } \\
\text { Increased cabin storage }\end{array}$ \\
& \multirow{2}{*}{$42 \%$} & Quality & $\begin{array}{l}\text { Space } \\
\text { Bunk }\end{array}$ \\
& & & $\begin{array}{l}\text { Setter carpet } \\
\text { A larger bunk }\end{array}$ \\
& & & Microwave placement \\
& \multirow{2}{*}{$36 \%$} & Lack of space for equipment & Morage space \\
Storage Facilities & & & Drawers that pull out \\
\hline
\end{tabular}

Table 13 Which of the following components of your truck's transmission are you satisfied with in terms of design?

\begin{tabular}{llll}
\hline Central theme & Frequency $(\%)$ & Subtheme & Recommendation \\
\hline Ease of use & $86 \%$ & Exactness of shifting & Easier and smoother gear transition \\
\hline Location & $42 \%$ & Location of gear shifter & $\begin{array}{l}\text { Automatic transmission } \\
\text { Adjustability }\end{array}$ \\
\hline Clutch & $35 \%$ & Reachability & $\begin{array}{l}\text { Better location of clutch } \\
\text { Adjustability }\end{array}$ \\
\hline
\end{tabular}

Table 14 Which of the following components of your truck's instrument console are you satisfied with in terms of design?

\begin{tabular}{llll}
\hline Central theme & Frequency $(\%)$ & Subtheme & Recommendation \\
\hline Dashboard & $69 \%$ & Reachability & Slanted and contoured dash design \\
\hline Lighting & $59 \%$ & Lighting & $\begin{array}{l}\text { More lights on and in dash back } \\
\text { Lighting better light on top of cabinets }\end{array}$ \\
\hline Cabinets & $39 \%$ & Reachability & $\begin{array}{l}\text { Cabinets doors instead of stretched } \\
\text { mesh material }\end{array}$ \\
\hline
\end{tabular}

Table 15 Which of the following components of your truck's engine accessibility are you satisfied with in terms of design?

\begin{tabular}{llll}
\hline Central theme & Frequency (\%) & Subtheme & Recommendation \\
\hline Fuel tank accessibility & $74 \%$ & $\begin{array}{l}\text { Pump handle jumping } \\
\text { Fuel spills }\end{array}$ & Ergonomic dash design \\
\hline Ease of lifting hood & $50 \%$ & $\begin{array}{l}\text { Weight of hood (heavy) } \\
\text { Hood latches (difficult) }\end{array}$ & Top of the dash too slanted \\
\hline Ease of closing hood & $43 \%$ & $\begin{array}{l}\text { Visibility } \\
\text { Weight of hood (heavy) } \\
\text { Hood latches (difficult) }\end{array}$ & $\begin{array}{l}\text { More lights in dash } \\
\text { Back lighting } \\
\text { Better light top cabinets }\end{array}$ \\
\hline
\end{tabular}

Table 16 Which of the following components of your truck's side mirror are you not satisfied with in terms of design?

\begin{tabular}{llll}
\hline Central theme & Frequency $(\%)$ & Subtheme & Recommendation \\
\hline Side mirror size & $31 \%$ & $\begin{array}{l}\text { Difficulty to get the complete view } \\
\text { Too narrow to see the tail of the trailer }\end{array}$ & $\begin{array}{l}\text { Design-longer and wider } \\
\text { (e.g., West Coast mirror design) }\end{array}$ \\
\hline Side mirror adjustability $28 \%$ & Limited adjustability & Electrical adjustment \\
\hline
\end{tabular}

Table 17 Which of the following components of your truck's accessibility are you not satisfied with in terms of design?

\begin{tabular}{llll}
\hline Central theme & Frequency (\%) & Subtheme & Recommendation \\
\hline Step spacing & $37 \%$ & Difficult to reach the cab floor due to spacing & $\begin{array}{l}\text { Have one more step } \\
\text { Steps made close together }\end{array}$ \\
\hline Step width & $48 \%$ & Steps too narrow & Wider steps-especially top step \\
\hline Handrail location & $44 \%$ & $\begin{array}{l}\text { Slippery handrail material } \\
\text { Safety concerns due to loss of grip while } \\
\text { climbing }\end{array}$ & $\begin{array}{l}\text { Return to century design for more } \\
\text { accessibility } \\
\text { Handrail inside the truck }\end{array}$ \\
\hline Handrail availability & $50 \%$ & $\begin{array}{l}\text { Difficulty getting into the truck due to lack of } \\
\text { handrail(s) }\end{array}$ & Increase the number of handrails \\
\hline
\end{tabular}


wide of a distance for women drivers. The second subtheme indicated that steps were too narrow for proper foot placement. In addition, the topic of handrail availability and location were prominent central themes for participants in this study. Respondents recommended the additions of steps and handrails. Wider steps and availability of the number of handrails and inclusion of handrails within the truck cab were also recommended as opportunities for improvement.

\section{Discussion and Findings}

This study focused on eliciting the perceptions of women truck drivers regarding the design and equipment needs and recommendations for Class 8 trucks. This study sought to add to this body of literature. The analysis tells us that most of the design issues could be remedied if various aspects of Class 8 trucks were made to be more adjustable. In this study, no differences were found in survey answers between women drivers taller than $5^{\prime} 6^{\prime \prime}$ and drivers shorter. Therefore, height of participants was not a limiting factor. In addition, no differences were found between genders in terms of truck cab perceptions. Survey participants in this study were satisfied with their trucks.

As a result of this pilot study, the following recommendations are related to the design aspects of Class 8 trucks. These are based on items that were repeatedly identified by the study participants, who were truck drivers and members of the WIT organization.

- Seat adjustability. Participants in this study recommended increasing the adjustability of the seat style and mechanism for the Class 8 truck. General recommendations by survey participants were in the categories of: adjustability, increased lumbar support, shock absorption of the truck seat to accommodate bumps and road conditions. Specific recommendations in terms of adjustability included designing seatbelts that are adjustable to fit all body types, changing the seat design for positioning to fit women drivers, and increase leg capacity and space under the steering column. Lastly, study participants recommended manufacturers include airbags as a standard design feature;

- Adjustable steering wheels. Study participants recommended that adjustable steering wheels be included in the overall design or as an option for purchase when selecting a Class 8 truck. In addition, increasing the current adjustability features of the steering wheel were also a primary recommendation. Study participants consistently reported positive comments about the tilt steering wheels in the current trucks driven by participants in this survey. Study participants in this survey suggested the involvement of women truck drivers in the design phase of steering wheels at the time of manufacture. In addition, participants recommended truck manufacturers and distributors allowing greater decision making and choices in terms of size and placement of the steering wheel during the purchasing process;

- Adjustable foot pedals. Participants in this study recommended a review of the adjustability of the pedal mechanisms. Study participants also recommended manufacturers review the raw materials used during the manufacturing process and select materials to make the pedals less slippery in times of inclement weather. Suggestions were also made to widen the space between pedals, specifically the clutch mechanism;

- Increased truck cab lighting and comfort. Study participants recommended improvements in the areas of lighting, storage facilities, and comfort. Recommendations included but were not limited to the following: (1) increasing the number and types of lights in the truck cab and sleeper compartments; (2) increasing the storage and accessibility of storage; and (3) improving the quality, comfort and size of the mattresses in the sleeper compartments;

- Easy access engine compartments. Accessibility of the engine compartment was a design priority for women truck drivers in this study. The weight of the truck hood and difficulty closing hood latches were 
specific concerns identified in this study. Study participants recommended accommodations in the ergonomic design of the hood and engine compartments. The recommendations included: (1) attempts to decrease the overall weight of the hood in the manufacturing process considering lighter materials without compromising quality and durability; (2) use of hydraulic lifters for easier opening and closing which would accommodate all body types; and (3) increased lighting within the engine compartment area. Study participants also recommended manufacturers consider automatic transmissions as a standard design option for Class 8 trucks;

- Adjustable side mirrors. Survey participants recommended increase adjustability of the side mirrors for the Class 8 truck design. Increased adjustability of side mirrors is recommended for good sight lines toward the rear of the truck. This would improve the safety for the driver in handling the truck during normal operations. In addition, longer and wider mirrors to view the end of the tractor trailer would improve safety and handling of the truck and increase efficiency and maneuverability by truck drivers;

- Step spacing and width. Study participants provided recommendations in terms of the design and width of the steps exiting the truck compartment. Specific recommendations for manufacturers based on this study included: (1) widening the top step for exiting the truck cab compartment to provide a wider platform base and improve safety for drivers exiting the compartment; (2) decreasing the width between steps to accommodate operators of shorter stature and stride capacity. This would reduce safety risks and fall potential;

- Handrails. Study participants also suggested the availability of handrails externally. Participants stated that handrails were not standard equipment for some Class 8 trucks. Including handrails inside the truck cab were also recommended to avoid slipperiness in times of inclement weather. Survey participants also suggested increasing handrails in areas where climbing may be a necessity.

\section{Conclusions}

This study found that there were no differences in the responses from women drivers above $5^{\prime} 6^{\prime \prime}$ tall and those that were below $5^{\prime} 6$ " in height. Adjustability was the primary theme and recommendation from the WIT respondents. While study participants were primary female in terms of gender, the common themes of this study apply to all gender types. Study participants indicated issues with the placement, adjustability, and size of at least one or two items in their trucks. A positive qualitative finding of the survey participants was the overwhelming response to tilt steering. This furthers the study's assertion that flexibility and adjustability are necessities for women truck drivers regarding the design of Class 8 trucks. Including truck drivers in cab compartment design at the manufacturer level would be beneficial for the potential driver, brand loyalty, manufacturers, and the trucking industry in general. Allowing choices regarding adjustability and providing options for accessories for prospective truck drivers at the time of lease or purchase is also recommended.

\subsection{Limitations of the Study}

This study experienced limitations in terms of study design and duration. This study was limited in terms of time and experience level of students as researchers. This study was part of an applied learning project as a component of a graduate course at a University in the Midwest (United States). Therefore, challenges were experienced due to the nature of this learning environment. There was a noted design error in question design and formatting which was discovered after initial survey distribution. This resulted in a delay in survey deployment, limited responses, and delayed data collection. Although the student researchers corrected the survey design error, this impacted the overall duration of survey availability to study participants which limited the number of responses and 
resulted in an $18 \%$ response rate. In addition, the survey was deployed in April 2012 at the time of a readily observed holiday. Data analysis was impacted due to end of semester deadlines for course work in the university setting.

\subsection{Recommendations for Further Study}

Despite the limitations of this pilot study, significant and relevant information was obtained that provide the foundation for further study and future research. The following suggestions are recommended for future consideration:

(1) Redesign the survey to include more detailed survey logic and deploy the survey over a longer duration of time;

(2) Include a larger sample for analysis. This study had 122 responses with some questions reporting 113 responses out of a total of 663 surveys distributed. Distributing the survey over a longer duration and/or multiple replications of this survey would yield more reliable data for analysis;

(3) Include survey constructs and questions that collect a wider demographic data set, such as: age, gender, medium income, etc. to allow for increased analysis against industry trends and BLS data;

(4) Partner with NIOSH (National Institute of Safety and Health), truck manufacturers, and representatives in the trucking industry to create a validated survey construct. It is recommended that focus groups and additional survey measures be considered to validate survey questions to improve the reliability and validity of this survey instrument;

(5) As a result of recommendation Item 4, revision and redistribution of the survey to a pilot group or other transportation organizations is recommended for wider distribution of the survey;

(6) Include questions specifically focused on the topic of recruitment of women into the truck driving industry as well as questions designed to elicit feedback on retention of women in the trucking industry would be beneficial for further study.
Women are an untapped resource to consider in addressing the current driver shortage in the industry. Improvements in the quality of the truck driver environment are recommended to be a high priority for every trucking company for the recruitment and retention of women truck drivers. There is a pressing need to enhance ergonomic cab designs for safe and efficient over-the-road operation for women truck drivers. In addition, there has been limited focus on the truck cab design needs for the trucking industry specifically focused on women. This study seeks to inform the body of literature regarding the truck cab design needs based on the feedback and perceptions of women truck driver members of the WIT organization.

\section{Acknowledgements}

The University of Wisconsin, Stout would like to thank Ellen Voie, CEO and President of Women in Trucking and the members of the Women in Trucking (WIT) organization for their advocacy of women in the transportation industry, participation in this applied research project, and the support of the applied learning and research process.

\section{References}

[1] American Trucking Associations. 2012. "Truck Driver Shortage Update.” Arlington: VA. Accessed September 1, 2015. http://www.truckline.com/StateIndustry/Document s/Driver\%20Shortage\%20Update\%20November\%20201 2.pdf.

[2] American Trucking Associations. 2007-2008. "Trucking and the Economy." 2007-2008 ed. Arlington: VA. Accessed September 1, 2015. http://www.trucking.org/ Newsroom/Trucks\%20Are/Trucking\%20and\%20the\%20 Economy.pdf.

[3] Beilock, R. 2005. "Are We Running Out of Truck Drivers?." University of Florida IFAS Extension, FE539. 1-6.

[4] Black, J., Maurer, M., Palakeel, J., and Chacon, W. 2012. Truck Cab Design Survey for Women Trucking Organization. Unpublished report. University of Wisconsin, Stout.

[5] Bunn, T. L., Yu, L., Slavova, S., and Bathke, A. 2009. "The Effects of Semi-truck Driver Age and Gender and the Presence of Passengers on Collisions with Other Vehicles." Traffic Injury Prevention 10 (3): 266-72. 
[6] Johnson, J. C., Bristow, D. N., McClure, D. J., and Schneider, K.C. 2011. "Determinants of Job Satisfaction among Long Distance Truck Drivers: An Interview Study in the United States." International Journal of Management 28 (1): 203-16.

[7] Stephenson, F. J., and Fox, R. J. 1996. "Driver Retention Solutions: Strategies for For-hire Truckload (TL) Employee Drivers." Transportation Journal 35 (4): 12-25.

[8] BLS (Bureau of Labor Statistics). 2011. Household Data Annual Averages 2011. Washington, DC: US Department of Labor.

[9] Bureau of Labor Statistics. 2009a. Career Guide to Industries, 2010-11 Edition: Truck Transportation and Warehousing. Washington, DC: U.S. Department of Labor, Bureau of Labor Statistics. Accessed September 1, 2015. http://www.bls.gov/oco/cg/cgs021.htm.

[10] Belman, D. L., and Monaco, K. A. 2001. "The Effects of Deregulation, De-unionization, Technology, and Human Capital on the Work Lives of Truck Drivers." Industrial and Labor Relations Review 52 (2a): 502-24.

[11] Bradtmiller, B., Ratnaparkhi, J., and Tebbetts, I. 1985. Demographic Assessment of the U.S. Army (NATICK/ TR86/04). Natick, MA: U.S. Army Natick Research Development and Engineering Center.

[12] International Organization for Standardization. 2006. ISO 15535: General Requirements for Establishing International Databases. Geneva, Switzerland: ISO.

[13] Jinhua, G., Hongwei, H., Bradtmiller, B., Tsui-Ying, K., Reed, M. R., Jahns, S. K., Loczi, J., Hardee, H. L., and Piamonte, D. P. 2012. "U.S. Truck Driver Anthropometric Study and Multivariate Anthropometric Models for Cab Designs." Human Factor 54 (5): 849-71. DOI: 10.1177/0018720812442685.
[14] Bureau of Labor Statistics. 1983. Current Population Study: Annual Average Industry and Occupation Tables for Year Ending Dec 83. Washington, DC: U.S. Department of Labor, Bureau of Labor Statistics.

[15] Bureau of Labor Statistics. 2009c. Current Population Study: Characteristics of the Employed, Household Data Annual Averages. Washington, DC: U.S. Department of Labor, Bureau of Labor Statistics. Accessed September 1, 2015. ftp://ftp.bls.gov/pub/special.requests/lf/aa2009/pdf/ cpsaat11.pdf.

[16] Paille, P., Fournier, P., and Lamontagne, S. 2011. "Relationships between Commitments to the Organization, the Superior, and the Colleagues and the Intention to Leave among Truck Drivers." International Journal of Organizational Analysis 19 (2): 92-108.

[17] Sanders M. S. 1977. A Nationwide Study of Truck and Bus Drivers. Final report prepared for Department of Transportation. Washington, DC: Department of Transportation, Federal Highway Administration, Bureau of Motor Carrier Safety.

[18] Sanders M. S. 1983. U.S. Truck Driver Anthropometric and Truck Work Space Data Study (CRG/TR-83/002). Final report. Westlake Village, CA: Canyon Research Group.

[19] Shaw, B., and Sanders, M. S. 1984. Female U.S. Truck Driver Anthropometric and Truck Work Space Data Study. Warrendale, PA: Society of Automotive Engineers.

[20] Mangin, K. 2012. "Truck Equipment Gets a Passing Grade." Redefining the Road. Women in Trucking Association 31: 28-9. Accessed September 1, 2015. http://www.womenintrucking.org/newsletter.cfm.

[21] Miles, M. B., and Huberman, A. M. 1994. Qualitative Data Analysis. An Expanded Sourcebook. Thousand Oaks: Sage Publications. 